\title{
AN OT ACCOUNT OF PHONOTACTIC AND CODA NEUTRALIZATION OF ENGLISH LOANS IN PILIBHIT HINDI- URDU
}

\author{
Mohd Hamid Raza \\ Aligarh Muslim University, Aligarh (U.P.), India \\ 9456828317, 7302508230 \\ razahamid086@gmail.com
}

\section{ABSTRACT}

This paper provided the basic information of the phonological processes as the Coda Neutralization and Phonotactics of English Loans in Pilibhit Hindi-Urdu within the framework of Optimality Theory (OT). The objectives of this paper were to represent the aspects of the coda neutralization in the sense of voiced obstruent segment becomes voiceless obstruent segment in the final syllable structure of the loanwords, and the consonant clusters break within the insertion of an extraneous segment in any location of the English Loans in Pilibhit Hindi-Urdu. In the another framework, this paper revealed the phenomena of devoicing features of coda consonants and the grades of the additional segments in Pilibhit Hindi-Urdu loanwords within the principles of Optimality Theory (Prince \& Smolensky, 1993). The central idea of this paper was to explore the process of conflicts between the candidates at the surface level and reflects the properties of the input candidate by the observation of the constraint rankings. In this study, it was propounded the effective formalities of the hierarchy of the constraint rankings and drew one of the best candidates as an optimal candidate out of the output candidates from English loans in Pilibhit Hindi-Urdu. The groundwork of this paper was related to the significant aspects of the English loans that were adapted within the addition, insertion, or deletion of the segments in Pilibhit Hindi-Urdu. In this paper, it was also determined the facts of the coda devoicing of the speech segments in terms of neutralization at the end of the syllable structure of English loans in Pilibhit Hindi-Urdu.

Keywords:

Optimality Theory, Phonotactics, Coda Neutralization, Loanwords. 


\section{INTRODUCTION}

District Pilibhit is the north-eastern division of Rohilkhand that is located at the sub-Himalayan region of the national boundary of Uttarakhand and the international boundary of Nepal. The official languages of District Pilibhit are Hindi, Urdu, Punjabi, and English. Hindi and Urdu are the two major official languages of the Indian constitution that are widely spoken in district Pilibhit. Hindi and Urdu are the two major Indo-Aryan bases languages that shared linguistic features through language contact situations. It is determined that the native speakers of Pilibhit Hindi-Urdu borrowed the English lexical items and altered their physical mechanism within the proper aid of Optimality Theory (OT) principles. Optimality Theory was introduced by Prince and Smolensky (1993) relevant to the hierarchy of the constraints that explored the ranking features of the input and output candidates. 


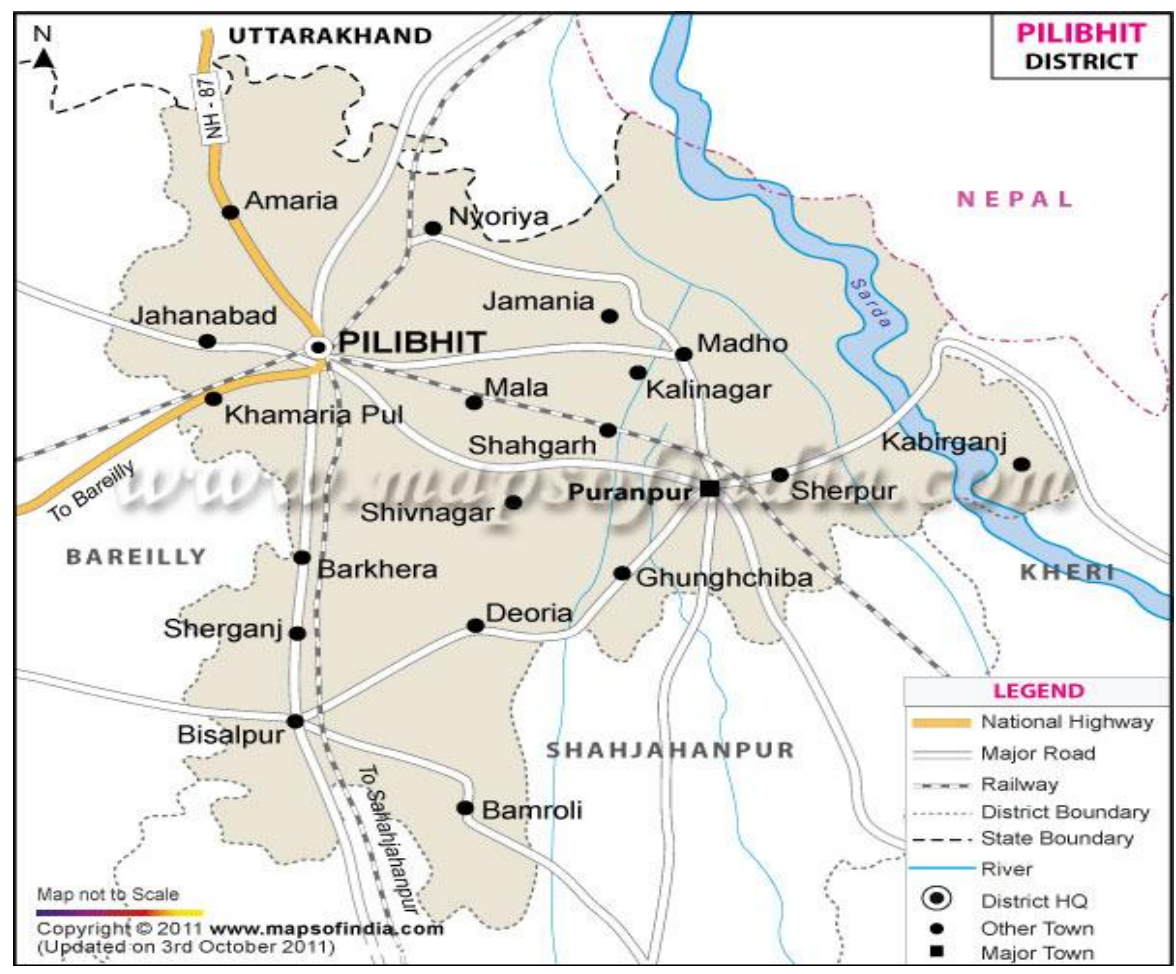

Fig.: 01 District Map of Pilibhit (U.P.)

OT has two significant constraints as 'faithfulness constraints' and 'markedness constraints.' The faithfulness constraints have the requirement of the linguistic features that maintained the similarity between input and output candidates, while the markedness constraints have the requirement of the linguistic features that formed the well-formedness structure of the output candidates. The term Phonotactics stands for the representation of a sequence of two or more than two consonants that format the process of consonant clusters. It is observed that Pilibhit Hindi-Urdu native speakers break the process of consonant clusters within the addition or insertion of an external segment in all the positions of the English loanwords. The concept of the coda neutralization is related to the voicing feature of the voiced obstruents that altered into voiceless obstruents in the final position of the 
syllable structure of the English loanwords in Pilibhit Hindi-Urdu. It is notified that Pilibhit Hindi-Urdu native speakers did not preserve the property of the consonant clusters and the voicing of the voiced obstruent segments in the syllable structure of English loanwords.

Hence, this research was conducted to examine the process of Phonotactics or consonant clusters that is broken by the addition or insertion of an extraneous segment in the syllable structure of English loans in Pilibhit Hindi-Urdu. In addition, the researcher also determined the aspect of the coda neutralization in the sense of voicing feature of the voiced obstruents that altered into voiceless obstruents in the final margin segment of the syllable structure in Pilibhit Hindi-Urdu loanwords in this research.

\section{LITERATURE REVIEW}

According to Campbell (1998), the phonological pattern of a language can be altered through the process of Phonotactics, syllable or morpheme structure by the acceptance of the loanwords in more intimate language contact situation which does not conform to the native patterns. For example, the native Finnish speakers did not permit the consonant clusters at the beginning of the words in indigenous languages, but through the intimate language contact they borrow the words from the Swedish and later from English then perform the pattern of Phonotactics or consonant clusters such as:

$$
\begin{array}{lll}
\text { /krokotili/ } & \text { 'crocodile' } & \\
\text { /kruunu/ } & \text { 'crown' } & \text { (from Swedish 'krona') } \\
\text { /presidentti/ } & \text { 'president' } & \\
\text { / smaragdi/ } & \text { 'emerald' } & \text { (from Swedish 'smaragd') }
\end{array}
$$


Meanwhile, the morphological edges determine the aspects of the segment at the level of 'Grammatical word' (GrWd), while the prosodic edges represent the additional properties of elements at the level of 'Prosodic Word' (PrWd).

There is a clear significance aspect of the alignment of an epenthetic vowel at the right edge of the prosodic word, but the violation occurs at the right edge of the grammatical word.

a) $\quad \operatorname{PrWd}$
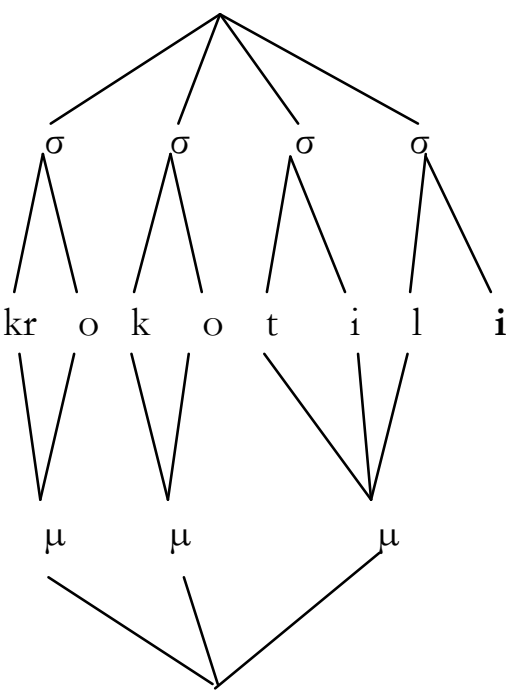

GrWd b) $\quad \operatorname{PrWd}$
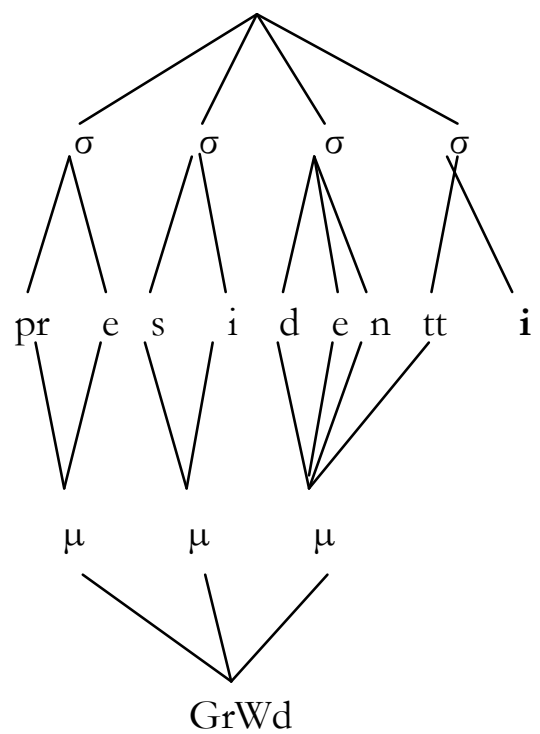

Fig.: 02 Structures of Prosodic and Grammatical Words

\section{Optimality Theory (OT)}

Optimality Theory (OT) was first introduced by Prince and Smolensky (1993) for describing the syllable structure of the words in a particular language, but soon it spread in other areas of Linguistics because its wide application became very effective at least in all fields of Linguistics. OT is related to the various types of tenets that preserved the linguistic features of 
the output candidates after compared with the features of the input candidate. First tenet is the "GEN" (Generator), which performs candidate analysis to generate many forms. According to McCarthy (2002), "Gen is universal," which means that all produced candidates by Gen for a given input are the same in all languages of the world. These candidates are varied from language to language, and the property of Gen is called "inclusive or freedom of analysis." Alan Prince and Paul Smolensky (1993) introduced second tenet "CON" (Constraint) that tells us what the substantive constraints are, from which grammars are built. The third significant key component of Universal Grammar (UG) is a precise definition of constraints, which we may sometime know as EVAL (Evaluation) that, spells out what it means to be optimal concerning a ranking of CON.

GEN

EVAL

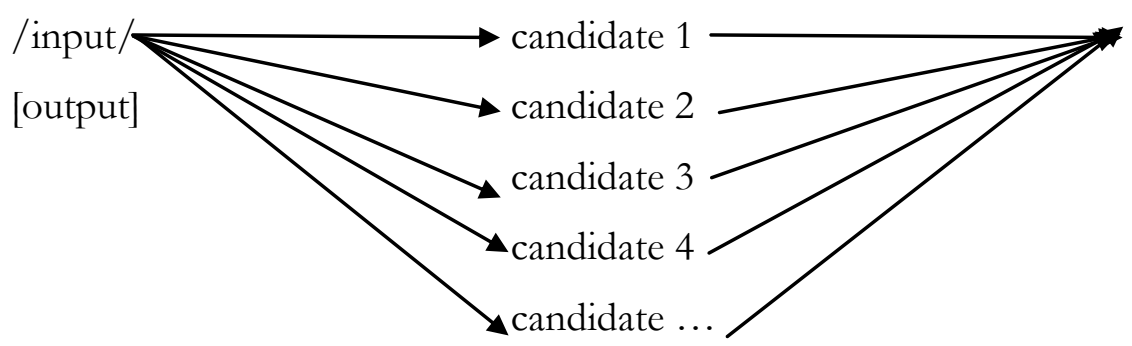

Fig.: 03 Interaction between input and output candidates

Furthermore, according to Carr (2008), OT is a model of the Generative Grammar that is consisted of the crucial constraint rankings. Certain types of constraints are listed in the tableau from left (most powerful) to the right (least powerful).

The table for the OT analysis of an input candidate /film/ with the help of constraints 
Table I

The Consideration of constraints and candidates with the reference of input

\begin{tabular}{|c|c|c|c|}
\hline / film/ & DEP-IO & MAX-IO & $\begin{array}{c}{ }^{*} \mathrm{COMP} \\
\text { CODA }\end{array}$ \\
\hline a. $\quad[\mathrm{fIl}]$ & & $* !$ & \\
\hline b. बस्तु [fIlm] & & & $*$ \\
\hline $\begin{array}{ll}\text { c. } & \text { [filəm] }\end{array}$ & $* !$ & & \\
\hline
\end{tabular}

According to Kager (1999), Optimality Theory is a developmental process of the Generative Grammar that focuses on the formal descriptions of the universal principles based on linguistic typology. He encounters a case of 'coda neutralization,' the final marginal consonant of the syllable structure at the monosyllables words in Dutch.

Table for the input candidate /bed/, assuming the Dutch ranking

Table II

The interaction between input and output candidates within the constraints

\begin{tabular}{|c|c|c|}
\hline /bed/ & *VOI-CODA & IDENT-IO (VOI) \\
\hline a. एहु $[\mathrm{bet}]$ & & $*$ \\
\hline b. & $* !$ & \\
\hline
\end{tabular}

\section{Phonotactics and Syllable Structures}

Phonotactics and syllable structures are the two key factors of the phonological conventions that performed the way of linguistic competence in the proper arrangement of the sequence of consonants and vowels in the languages. The term Phonotactics refers to the language-specific restrictions 
on the sequencing of speech sounds (Haugen, 1956 \& Hill, 1958). The Phonotactics in a language is the way of enforced by the phonological rules in the lexical items (Carr, 1993, p. 193). In terms of the phonological rules, Phonotactics is the aspect of the composition of certain types of the segments and constructed a syllable structure in a particular language. A word may be monosyllabic that consists within the single syllable as $\mathrm{CV}, \mathrm{VC}, \mathrm{CVC}$, $\mathrm{CCV}$, etc., disyllabic that is coalescence within two syllables such as CVCV, CCVC, CVCVC, etc. or multisyllabic that are conjoined within more than two syllables such as CVCVCC, VCCVCVCVCVC, etc.

\section{Coda Neutralization}

One of the basic concepts of the phonological theory is the neutralization, whereby phonemic distinctions are eliminated in a particular phonological context (Trubetzkoy, 1939). In this study, we have determined the process of neutralization of voicing features of voiced obstruents that altered into voiceless obstruents at the coda position of the syllable structure in the English loans adopted in Pilibhit Hindi-Urdu. It is explored that the neutralization within the phonological property of word-final coda devoicing is the complete phenomena as compared to the phonetically incomplete process by the evidence of vowel duration, duration of vowels in the closure and the closure duration in the languages (e.g. Catalan: Dinesen \& Charles Luce 1984; German: Port \& O’ Dell 1985; Charles Luce 1985; Port \& Crawford 1989; Polish: Slowiaczek \& Dinnesen 1985; Russian: Pye 1986). The account of the coda neutralization in the sense of loss of voicing of the obstruent segments is presented in many languages as Dutch in which the speakers did not maintain the rules and regulations of the phonological processes. 


\section{RESEARCH METHODOLOGY}

The researcher has collected the data from the native speakers of Pilibhit Hindi-Urdu through the interview and observation. The nature of data is the primary and actual representation of native speakers of Pilibhit Hindi-Urdu. The data is evolved within the full observation of origin and first time collected from the exact environment of the target population in the region of the district Pilibhit. The researcher has used the high quality of the instrument as a tape recorder and put its approach to the mouth of the native speakers for the data collection. After the collection of the data, the researcher transcribed it into phonemic transcription and applied the principles of the Optimality Theory to solve the problems of the syllable structures of English Loans related to the Phonotactics and coda neutralization.

The researcher has collected data from the twenty participants between the ages group of 25 to 40 . The data are referred to as the ten males and ten females as the equal proportion of the gender probability to the Pilibhit Hindi-Urdu native speakers. All the participants were actual inhabitants of the district Pilibhit that are in regular contact with other language speakers too. They always spoke in their native language at the time of asking about the use of English loans with or without modification and how interpreted in their LANGUAGE. 


\section{FINDINGS AND DISCUSSION}

\section{The role of Phonotactic in the syllable structure}

According to Mattys and Jusczyk (2001), Phonotactics and syllable structures formed an integral part of the phonological competence and may be used to discover other aspects of a language. According to Campbell (1998), the phonological pattern of a language can alter through the process of Phonotactics, morpheme, or syllable structure. The term Phonotactics and syllable structures represent the phenomena of the consonants and vowels and determine how the different segments are merged in a specific environment. For example, Pilibhit Hindi-Urdu native speakers did not maintain the procedure of Phonotactics at all the positions in English loans. They always added or inserted an extraneous segment that breaks the consonant clusters in the syllable structure of the English loans and changed the shape of structure:

$\begin{array}{lcl}\text { English } & \text { Pilibhit Hindi-Urdu loans } & \text { Gloss } \\ \text { /terbl/ } & \text { [tebəl] } & \text { 'table' } \\ \text { /pædl/ } & \text { [paidəl] } & \text { 'paddle' } \\ \text { /sku:l/ } & \text { [Isku:l] } & \text { 'school' } \\ \text { /steIJən/ } & \text { [Istesən] } & \text { 'station' } \\ \text { /speIJəl/ } & \text { [Ispesəl] } & \text { 'special' }\end{array}$

We will now move towards the consideration of coincidence between Grammatical Word (GrWd) and Prosodic Word (PrWd) that are consisted within the process of epenthesis: 
a)

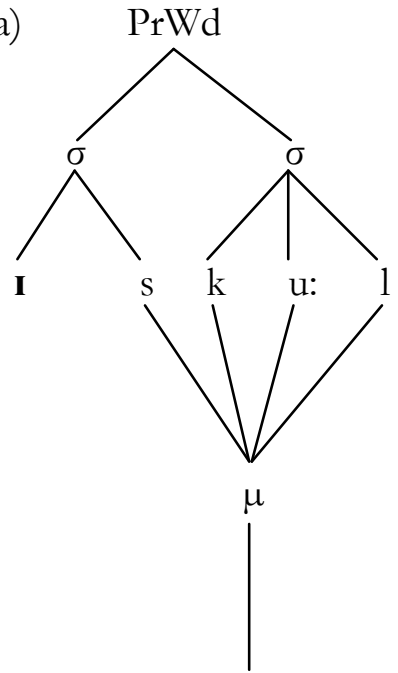

GrWd

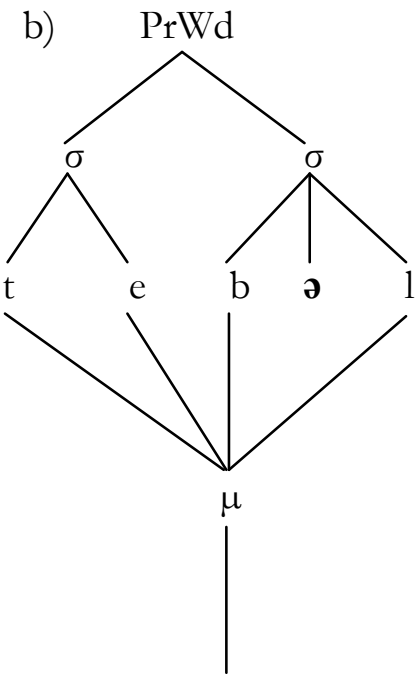

GrWd

Fig.: 04 Analysis of English Loans based on Phonological Processes

There is conflict among the output candidates due to the epenthesis that concentrates on the input candidate. This can be resolved only with the help of the constraints of the OT.

a) /teIbl/ satisfied with the higher, lower, and lowest rank of the constraints DEP-IO, ALIGN-R, and CONTIGUITY, while violated to the highest rank of the constraint *PEAK (CONS).

b) /te.bəl/ satisfied with the highest and lower rank of the constraints *PEAK (CONS) and ALIGN-R, while violated to the higher and lowest rank of the constraints DEP-IO and CONTIGUITY.

c) /teb.lu/ satisfied with the highest and lowest rank of the constraints *PEAK (CONS) and CONTIGUITY, while violated to the higher and lower rank of then constraints DEP-IO, and ALIGN-R.

Table for OT analysis of an input candidate /teIbl/ in ranking features 
Table III.

The phonological representation of input and output candidates within the constraints

\begin{tabular}{|l|c|c|c|c|}
\hline \multicolumn{1}{|c|}{$/$ terbl/ } & $\begin{array}{c}\text { *PEAK } \\
\text { (CONS) }\end{array}$ & DEP-IO & ALIGN-R & CONTIGUITY \\
\hline a. [teIbl] & $* !$ & & & \\
\hline b. $[$ [te.bəl] & & $* !$ & & $*$ \\
\hline c. $\quad[$ te.blu] & & $* !$ & $*$ & \\
\hline
\end{tabular}

The most dominated and powerful constraint occurs at the left side in the hierarchy, such as:

*PEAK $(\mathrm{CONS})>>$ DEP-IO $>>$ ALIGN-R > >CONTIGUITY

We have applied the tenets of OT to find out one of the best candidates as compared to others in Pilibhit Hindi-Urdu loans:

a) /sku:l/ satisfied with the higher, lower, and lowest rank of the constraints DEP-IO, CONTIGUITY, and ALIGN-L, while violated to the highest rank of the constraint *COMP-ONS.

b) /Isku:l/ satisfied with the lower and highest rank of the constraints CONTIGUITY and *COMP-ONS, while violated to the higher and lowest rank of then constraints DEP-IO and ALIGN-L.

c) /soku:l/ satisfied with the lowest and highest rank of the constraints ALIGN-L and *COMP-ONS, while violated to the higher and lower rank of the constraints DEP-IO and CONTIGUITY.

The various phonologists stated that the conflicts between the candidates could be solved only based on the constraints of OT. 
Table for the OT analysis of an input candidate /sku:l/ in ranking features

Table IV

The basic representation of the constraints within the formulation of candidates

\begin{tabular}{|c|c|c|c|c|}
\hline /sku:l/ & *COMP-ONS & DEP-IO & CONTIGUITY & ALIGN-L \\
\hline a. $\quad[$ sku:l] & $* !$ & & & \\
\hline b. [Is.ku:l] & & $* !$ & & * \\
\hline $\begin{array}{l}\text { c. [sv.ku:l] } \\
\end{array}$ & & $* !$ & * & \\
\hline
\end{tabular}

The hierarchy of constraints can be drawn in the sequence of the dominance ranking features such as:

*COMP_ONS $>>$ DEP-IO > > CONTIGUITY > > ALIGN-L

\section{The status of the coda neutralization in OT formation}

When a consonant is normally voiced and when it is pronounced without vocal-fold vibration in some context, it is said to be devoiced (Gussenhoven \& Jacobs, 2017). The coda devoicing or neutralization is a type of phonological feature like others in which a voiced segment released its voicing property and altered into the voiceless segment in a particular syllable structure of the words. For example, the researcher explored the devoicing of the voiced obstruents in the several tokens of English loans in Pilibhit Hindi-Urdu such as:

$\begin{array}{lcc}\text { English } & \text { Pilibhit Hindi-Urdu loans } & \text { Gloss } \\ \text { /tju:b/ } & {[\mathrm{tu}: \mathrm{p}]} & \text { 'tube' } \\ / \mathrm{pad} / & {[\mathrm{pat}]} & \text { 'pad' } \\ / \mathrm{ka}: \mathrm{d} / & {[\mathrm{ka}: \mathrm{t}]} & \text { 'card' } \\ \text { /bo:d/ } & {[\mathrm{bo:t}]} & \text { 'board' }\end{array}$


[roud/ [ro:t] 'road'

We will now move towards the consideration of the syllable structure of the words within the framework of the Prosodic Word (PrWd) and Grammatical Word (GrWd).

c)

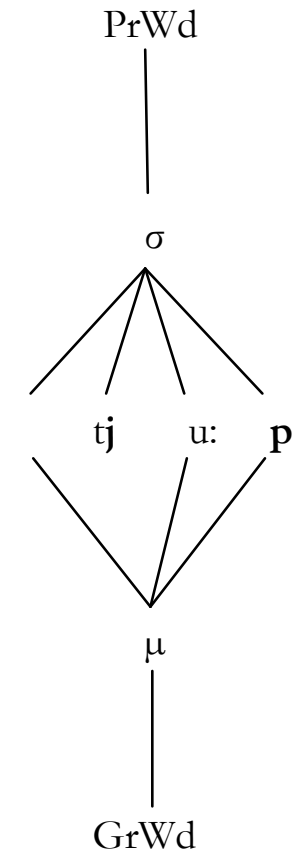

e)

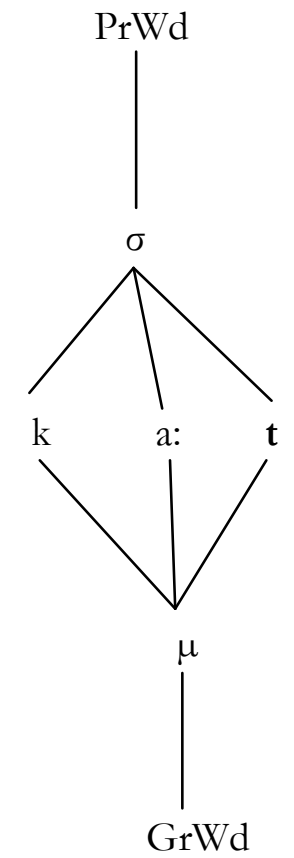

Fig.: 05 Loss of Voicing Feature of Voiced Obstruentsin Pilibhit Hindi-Urdu

We will now use the principles of Optimality Theory to solve the problems of the coda neutralization for input candidate $/ \mathrm{ka}: \mathrm{d} /$ in Pilibhit Hindi-Urdu.

a) [ka:d] satisfied with the lowest and higher rank of the constraints IDENT-IO (VOI) and *SG (No Spread Glottis), while violated to the highest and lower rank of the constraints *VOI-CODA and VOP (VOICED OBSTRUENT PROHIBITION). 
b) $\quad[\mathrm{ka}: \mathrm{t}]$ satisfied with the highest, higher, and lower rank of the constraints *VOI-CODA, *SG, and VOP, while violated to the lowest rank of the constraint IDENT-IO (VOI).

c) [kha:d] satisfied with the lowest rank of the constraint IDENT-IO (VOI), while violated to the lower, highest, and higher rank of the constraints VOP, *VOI-CODA and *SG.

Table for the OT analysis of input candidate /ka:d/, assuming in Pilibhit Hindi-Urdu

Table V

The consideration of voicing representation of coda condition in the syllable

\begin{tabular}{|l|c|c|c|c|}
\hline$/ \mathrm{ka}: \mathrm{d} /$ & $\begin{array}{c}* \text { VOI- } \\
\text { CODA }\end{array}$ & $*$ SG & VOP & $\begin{array}{c}\text { IDENT-IO } \\
\text { (VOI) }\end{array}$ \\
\hline a. $[\mathrm{ka}: \mathrm{d}]$ & $* !$ & & $*$ & $*$ \\
\hline b. $[\mathrm{ka}: \mathrm{s}]$ & & & & \\
\hline c. $\quad[\mathrm{kha}: \mathrm{d}]$ & $* !$ & $*$ & $*$ & \\
\hline
\end{tabular}

In the above table, we have the sequence of constraints as in the hierarchy of constraints based on dominating features indicated by $>>$ such as:

$$
\text { *VOI-CODA }>>\text { *SG > > VOP >> IDENT-IO (VOI) }
$$

In the structure of the diagrams above, we have seen that there is the process of epenthesis in which an additional segment broke the consonant cluster of English loanwords in Pilibhit Hindi-Urdu. It is found out that the English monosyllabic loan word became disyllabic or trisyllabic word after the prosthesis of the vowel segments at the initial or non-initial positions of the words in Pilibhit Hindi-Urdu. In table 3, we have analyzed that the 
candidate (a) violated to the highest rank of the constraint *PEAK (CONS) that is consisted of the fatal violation, while satisfied with the higher, lower and lowest rank of the constraints DEP-IO, ALIGN-R and CONTIGUITY. The candidate (b) is satisfied with the highest and lower rank of the constraints *PEAK (CONS) and ALIGN-R, while violated to the higher and lower rank of the constraints DEP-IO and CONTIGUITY. It has the highest rank of the linguistic features that are correspondent to the input candidate within the least number of the violations and fatal violations, so it is declared as an optimal candidate. The optimal candidate is the best and indicated by a finger symbol The candidate (c) is satisfied with the highest and lowest rank of the constraints *PEAK (CONS) and CONTIGUITY, while violated to the higher and lower rank of the constraints DEP-IO and ALIGN-R. It has the least number of the assuming features as compare to the input candidate. So, in this context the candidate (c) is not an optimal candidate.

In table 4, we have determined that the candidate (a) is violated to the highest rank of the constraint *COMP-ONS, while satisfied with the higher, lower and lowest rank of the constraints DEP-IO, CONTIGUITY, and ALIGN-L. It has the highest rank of the constraints within the least rank of the linguistic features as correspondent to the input candidate. So, it is not the best candidate as the reference of the optimal candidate. The candidate (b) is satisfied with the highest and lower rank of the constraints *COMPONS, and CONTIGUITY, while violated to the higher and lowest rank of the constraints DEP-IO and ALIGN-L. It has the least number of the violations and fatal violations within the highest number of the linguistic features that are correspondent to the input candidate. So, it is declared as the best candidate and became the optimal candidate that is indicated by 
The candidate (c) has a higher rank of the violation, and fatal violation within the lower rank of the ranking features as the correspondent to the input candidate. So, in this framework it is the sub-optimal candidate, but not optimal.

In table 5, the candidate (a) violated to the highest and the lower rank of the constraints *VOI-CODA and VOP, while satisfied with the higher and lowest rank of the constraints *SG and IDENT-IO (VOI). It has the most ranking features of the violations and fatal violations and the least ranking features as correspondent to the input candidate. So, in this context, it is not an optimal candidate. The candidate (b) is satisfied with the highest, higher and lower rank of the constraints *VOI-CODA, *SG, and VOP, while violated to the only lowest rank of the constraint IDENT-IO (VOI). It has the least number of the violations and fatal violations with the highest number of the ranking features as correspondent to the input candidate. So, the candidate (b) is the best and declared as an optimal candidate. The optimal candidate is indicated by highest rank of the violations and fatal violations within the least number of the ranking features as compared to the other candidates. They are out of the source of the winning candidate and lost the opportunity to become an optimal candidate.

\section{CONCLUSION}

It is notified that the consonant clusters are broken within the addition of a segment in the initial position of the English loans in Pilibhit HindiUrdu. There is not the process of maintaining the consonant clusters by the native speakers of Pilibhit Hindi-Urdu because they always enter an external element that modified the version of the syllable structures in the loanwords. 
There is a strong way of conflicts between the groupings of the consonant in the output candidates that are referred towards the input candidate to draw the best candidate. The criteria for selecting the best candidate as an optimal candidate are relevant to the principles of the Optimality Theory (OT).

It is evaluated that Pilibhit Hindi-Urdu native speakers lost the voicing feature of the voiced obstruent segments at the coda position of the English Loans. They did not maintain the voicing feature of the coda consonants in the syllable structure of the loanwords. Different types of the output candidates are listed within the hierarchy of the constraints; one of them is the best candidate known as an optimal candidate. The optimal candidate has linguistic features that are correspondent to the input candidate and indicated by a specific optimal symbol.

\section{REFERENCES}

Campbell, L. (1998). Historical Linguistics: An introduction. Edinburgh: Edinburgh University Press.

Carr, P. (1993). Phonology. London: The Macmillan Press LTD.

Gussenhoven, C. \& Jacobs, H. (2017).Understanding Phonology (7 ed).Oxon: Routledge.

Kager, R. (1999). Optimality theory. Cambridge: Cambridge University Press.

Mattys \& Jusczyk. (2001). Phonotactic cues for segmentation of fluent speech by infants. Cognition, 78(2), 91-121.

McCarthy, J. J. (2002). A Thematic guide to optimality theory. Cambridge: Cambridge University Press

Prince, A. \& Smolensky, P. (1993).Optimality theory: Constraint interaction in generative grammar. Rutgers University Center for Cognitive Science Technical Report 2. 
Trubetzkoy, N. S. (1962). Principles of Phonology (3 ed.). California: University of California Press. 